The Egyptian Journal of Hospital Medicine (April 2021) Vol. 83, Page 812-816

\title{
Values of Application of Three Delays Model to Maternal Mortality Scenarios at Sohag Univeristy Hospital Bidirectional Cohort Study
}

Magdy Mohamed Amin, Mohamed Sabry Ibrahim, Ahmed Elsayed Ali*

Department of Obstetrics and Gynecology, Faculty of Medicine - Sohag University

*Corresponding author: Ahmed Elsayed Ali, Mobile: (+20) 01023557172, E-Mail: ahmedalsaid912@ gmail.com

\begin{abstract}
Background: Maternal mortality in Egypt is still relatively high so measuring maternal mortality and identifying its causes is essential and should be calculated regularly for the purpose of planning, monitoring and evaluation of provided maternal health care. Objective: Identifying the circumstances and causes of maternal mortality.

Patient and method: Data were collected from records of patients who were presented to and delivered at Sohag University Hospital in the period between 2017 and 2019. Only cases of maternal mortality were included in this study. In our study we found 20 maternal deaths occurred at our hospital between 2017 and 2019.

Results: In our study the most frequent one was the $1^{\text {st }}$ delay that occurred in 10 women followed by $2^{\text {nd }}$ delay in 4 women then combination of $1^{\text {st }}$ and third in about 3 women and combination of $1^{\text {st }}$ and $2^{\text {nd }}$ in 2 cases and delay 2 in 1 case. Our study showed that the first cause of death was preeclampsia/eclampsia $55 \%$ followed by obstetric hemorrhage (placenta previa, postpartum hemorrhage, rupture uterus) 35\%, caesarean section complications 5\% and lastly medical condition associated with pregnancy $5 \%$.

Conclusions: This study showed that the first delay is the most important delay in Sohag, especially in rural areas, and the most important cause of death was preeclampsia and ignorance about its complications which was due to lack of antenatal care.
\end{abstract}

Keywords: Delays, Health facilities, Maternal mortality, Preeclampsia, Postpartum hemorrhage,

\section{INTRODUCTION}

Maternal mortality is defined as death of a woman while pregnant or within 42 days of termination of pregnancy irrespective of the duration and site of the pregnancy, from any cause related to or aggravated by the pregnancy or its management but not from accidental or incidental causes; this can be either direct or indirect maternal death ${ }^{(\mathbf{1})}$.

Maternal mortality is a preventable tragedy that must be addressed, therefore improving maternal health is the fifth millennium development goal that has a target to reduce maternal mortality ratio by threequarters between 1990 and $2015^{(2)}$. Working for the survival and well-being of mothers is an economic, moral, social and human rights issue that requires continuous effort ${ }^{(3)}$. Almost all maternal mortality cases are preventable. Nearly 74 percent of maternal death could be averted if all women had access to the intervention for preventing or treating pregnancy and birth complication especially emergency obstetric care in many countries with high maternal mortality rates, there is a need to increase provision of appropriate quality services ${ }^{(4)}$.

Maternal mortality in Egypt is still relatively high, a 2005 study of global maternal mortality by the world health organization, in collaboration with UNICEF and the World Bank revised the official national maternal mortality rates. The report put maternal mortality in Egypt at 130/100,000 live birth, compared to a rate of $84 / 100,000$ as announced by the Egyptian ministry of health ${ }^{(5)}$.

Many of these deaths can be prevented, if women had timely access to high-quality obstetric care ${ }^{\left({ }^{(}\right)}$. A recent study showed that the two main avoidable factors for maternal deaths in Eygypt are substandard health care $(59 \%)$ and delay in seeking care $(42 \%)$. Death was higher in mothers aged more than 40 years also in multipara women ( $>5$ children). The tragedy is that woman who died were more likely to have delivered in a health facility (62\%) and less likely to have delivered at home ${ }^{(7)}$.

Numerous authors have demonstrated gaps in the provision of obstetric care to women treated in hospital ${ }^{(8,9)}$. Poor quality of care can contribut to maternal mortality both directly (inappropriate medical practice) and indirectly (deterred/delayed health service utilization). Improvements in quality of care have been shown to reduce in-hospital maternal mortality by as much as $50 \%{ }^{(9)}$. Measuring maternal mortality and identifying its causes is essential and should be done regulary for the purpose of planning, monitoring and evaluation of provided maternal health care (10). As well as calculating quality of care indicators such as case fatality rate, which is used to measure facility performance, in particular quality and promptness of care. It is most useful when compariosons are made over time for the same facility (11). Analyzing obstetric admission, survival and death rates aids managers, health services and professional staff in improving access to health services and providing quality health care locally and nationlwide. Additional efforts are essential to improve the identification of risk factors leading to poor maternal outcomes ${ }^{(\mathbf{1 2})}$.

The three delays conceptual framework: Recently avoidable materenal mortalities have been summarized in what is called a three-delay framework: Delay 1; delay in deciding to seek care by the women and/or her This article is an open access article distributed under the terms and conditions of the Creative Commons Attribution (CC BY-SA) license (http://creativecommons.org/licenses/by/4.0/) 
family. Delay 2; delay in reaching an adequate health facility. Delay 3; delay in receiving an adequate health facility.

Aims of the study was to identification of the different barriers that women face in achieving the timely and effective medical care needed to prevent maternal mortality aiming to improve the obstetric care and thus reduce maternal mortality as well as identifying the circumstances and causes of maternal mortality.

\section{PATIENTS AND METHODS}

This study was hospital based bidirectional-cohort study. Data were collected from records of patients who were presented to and delivered at Sohag University Hospital at the period between 2017 and 2019. Only cases of maternal mortality were included in this study. In our study we found 20 maternal deaths occurred at our hospital between October 2017 and October 2019.

Research question: What is the type of delay that will lead to maternal mortality in Sohag University Hospital?

Inclusion criteria: Recording all pregnant woman or at labor and post-partum who died at Sohag University Hospital, maternal mortality cases irrespective of the duration and site of the pregnancy from any cause related to or aggravated by the pregnancy or its management but not from accidental or incidental causes.

Exclusion criteria: All cases that died from accidental or incidental causes.

\section{Data collection:}

A)

admission.

B) Examination :

- General condition.

- Vital signs

- Abdominal examination

- Vaginal examination

C) Investigation

- CBC, liver function test (ALT AST, albumin, bilirubin), prothrombin time and concentration

- Ultrasonography and CT.

D) Other data:

- Obstetric complications/medical complications.

- Type of delivery.

- ICU admission.

- Cause of death.

Ethical consideration: The proposal was reviewed and approved by Sohag Medical Research Committee, and approval of Obstetric Department, Sohag University Hospital was also obtained. Data were collected from patient affairs records office. All data were confidential and were not used except for research purposes.

\section{Statistical analysis}

Analysis of the data collected was done using SPSS (statistical Package for the Social Sciences) program version 13. Description of quantitative variable was made as frequency.

\section{RESULTS}

Demographic data are shown in Table 1.

Table (1): Demographic of the dead mothers.

\begin{tabular}{|l|c|}
\hline \multicolumn{1}{|c|}{ Variables } & $\begin{array}{c}\text { Frequency (\%) } \\
(\mathbf{n = 2 0 )}\end{array}$ \\
\hline \hline Age groups & \\
Less than or equal 35 years & $16(80 \%)$ \\
Above 35 years & $4(20 \%)$ \\
\hline Governorate residence & \\
Qena & $2(10 \%)$ \\
Sohag & $18(90 \%)$ \\
\hline Residence & $15(75 \%)$ \\
Rural & $5(25 \%)$ \\
Urban & \\
\hline
\end{tabular}

Table 2 shows state of the women at admission, ICU admission and mode and place of delivery

Table (2): State of the women at admission, ICU admission and mode and place of delivery

\begin{tabular}{|l|c|}
\hline \multicolumn{1}{|c|}{ Variables } & $\begin{array}{c}\text { Frequency (\%) } \\
\text { N= 20 }\end{array}$ \\
\hline \hline Type of admission & $15(75 \%)$ \\
Emergency & $5(25 \%)$ \\
Routine & \\
\hline State at admission & $10(50 \%)$ \\
Not in labor & $6(30 \%)$ \\
In labor & $4(20 \%)$ \\
Post-partum & $9(45 \%)$ \\
\hline General condition & $2(10 \%)$ \\
Good & $9(45 \%)$ \\
Shocked (conscious) & \\
Shocked (unconscious) & $17(85 \%)$ \\
\hline ICU admission & $3(15 \%)$ \\
Yes & \\
No & $4(20 \%)$ \\
\hline Mode of delivery & $16(80 \%)$ \\
Vaginal & $16(80 \%)$ \\
C S & $1(5 \%)$ \\
\hline Place of delivery & $3(15 \%)$ \\
Public Hospitals & \\
Private clinic & At home \\
\hline
\end{tabular}

Eighteen women (90\%) had different forms of obstetric complications in that pregnancy where the preeclampsia was the most frequent (Figure 1). 


\section{The obstetric complications}

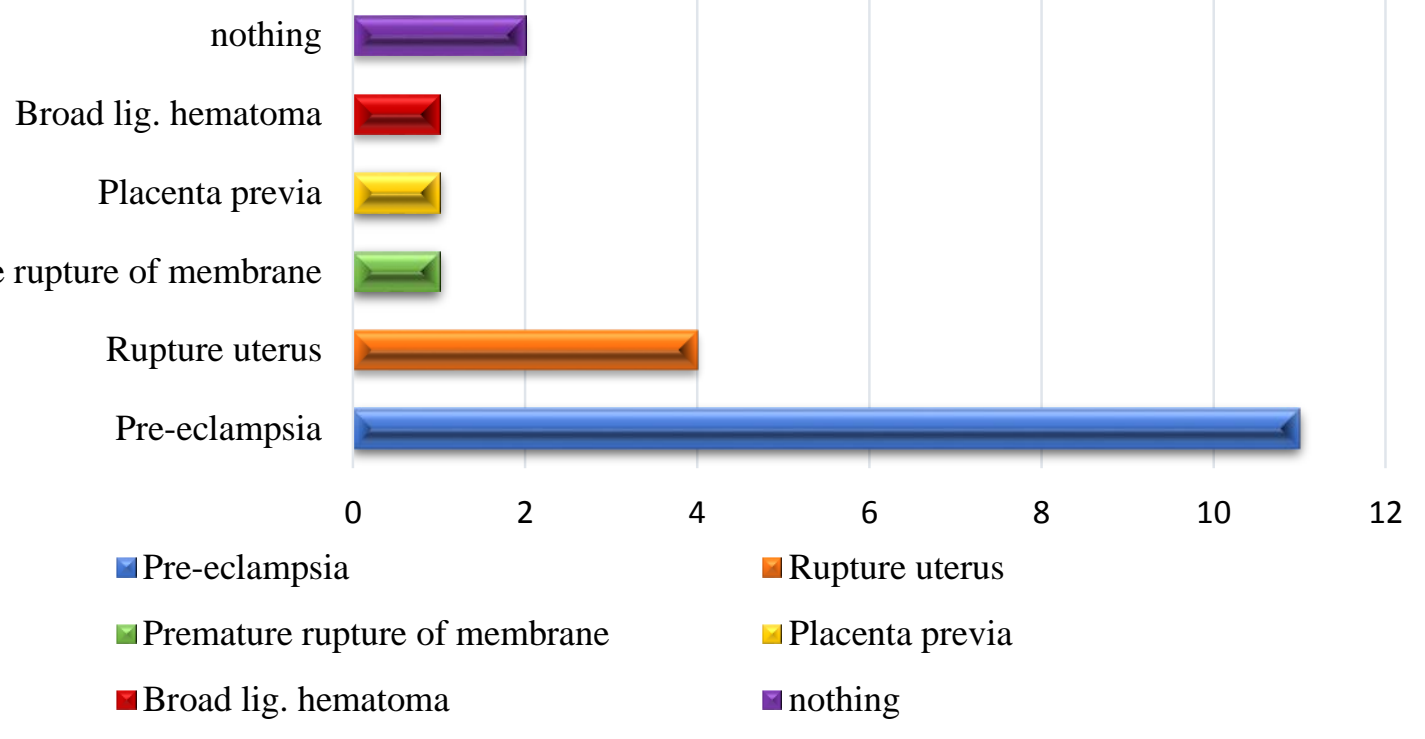

Figure (1): Obstetric complications of that pregnancy.

In our cases the most frequent delay was $1^{\text {st }}$ delay (Table 3 ).

Table (3): Delay in the different levels of the management

\begin{tabular}{|l|c|}
\hline \multicolumn{1}{|c|}{ Delay (s) } & $\begin{array}{c}\text { Frequency (\%) } \\
(\mathbf{n = 2 0})\end{array}$ \\
\hline \hline $1^{\text {st }}$ delay & $10(50 \%)$ \\
$2^{\text {nd }}$ delay & $1(5 \%)$ \\
$3^{\text {rd }}$ delay & $4(20 \%)$ \\
$1^{\text {st }}$ and $2^{\text {nd }}$ delays & $3(15 \%)$ \\
$1^{\text {st }}$ and $3^{\text {rd }}$ delays & $2(10 \%)$ \\
\hline
\end{tabular}

Causes of maternal death were classified into main categories either direct (as post-partum hemorrhage, eclampsia) or indirect causes. The direct causes of maternal death were frequent 19 times and the most frequent direct cause of death was eclampsia (Table 4).

Table (4): Cause of maternal death

\begin{tabular}{|l|c|}
\hline \multicolumn{1}{|c|}{ Causes of death } & Frequency \\
\hline \hline Direct causes & $\mathbf{1 9}$ \\
PIH (pregnancy induced hypertension & $\mathbf{1 1}$ \\
Eclampsia & $11(55 \%)$ \\
Obstetric hemorrhage & 7 \\
Postpartum hemorrhage & $4(20 \%)$ \\
Rupture uterus & $2(10 \%)$ \\
Antepartum hemorrhage (placenta & $1(5 \%)$ \\
previa) & $\mathbf{1}$ \\
Caesarean section complications & $1(5 \%)$ \\
Internal hemorrhage & \\
\hline Indirect causes & $\mathbf{1}$ \\
Ischemic heart disease & $1(5 \%)$ \\
\hline
\end{tabular}

Table 5 shows the frequency, associations, and number of fits of eclampsia.
Table (5): Frequency, association and number of fits of eclampsia

\begin{tabular}{|l|c|}
\hline Variable & $\begin{array}{c}\text { Frequency } \\
(\mathbf{n = 1 1})\end{array}$ \\
\hline \hline Associations & 7 \\
Alone & 4 \\
With HELLP syndrome & \\
\hline Number of fits & 4 \\
zero & 1 \\
Once & 2 \\
Twice & 4 \\
>twice & \\
\hline
\end{tabular}

\section{DISCUSSION}

In our study, the largest number of deaths occurred in the age group of 20-35, may be because those are the ages at which women are most likely to give birth, so efforts directed at this age group would most effectively reduce the number of deaths. According to Kachhwaha and Jain ${ }^{(13)}$ a young pregnant women carries higher risk due to preeclampsia, cephalopelvic disproportion, uterine inertia and anemia. This is compatible with our study, in age group equal to or less than 35 there were 9 cases of preeclampsia and 6 cases of obstetric hemorrhage.

The place of residence also has a role in maternal death as in our study 15 women (75\%) came from rural areas where low socioeconomic levels, ignorance and lack of emergency transport, which are logistic factors responsible for cases taking significantly longer to make a health contact, even after having decided to do so. Also 2 cases were from Qena Governorate, they came to Sohag University Hospital and that was a 
waste of time. That is compatible with Kachhwaha and Jain ${ }^{(13)}$ that showed maximum deaths occurred in patients with rural locality by $71 \%$ and Karlsen $\boldsymbol{e t} \boldsymbol{a l}$. (14) who showed presence of differences between urban and rural areas especially in the poor countries. In addition woman's education in urban areas is higher than in rural areas and this is an important factor, where educated woman can determine the risks and complications early and usually aware about health services more than the illiterate woman.

Our study revealed that 16 cases $(80 \%)$ of the maternal death were associated with caesarean section and this is agreed with Souza et al. ${ }^{\left({ }^{15}\right)}$ who showed that highly significant rates of deaths among women who delivered by caesarean section in both developed and developing countries. A study in the UK showed that the case fatality rate for all caesarean section is

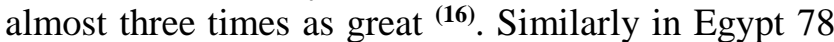
$\%$ of the death had undergone a caesarean section (CS) in Tanta University Hospital ${ }^{(3)}$ and $40 \%$ in Kasr ELAini (Cairo) ${ }^{(17)}$. These finding definitely draw attention to reviewing the indication of performing CS and prevention of complication associated with such procedure.

Our study showed that the first cause of death was preeclampsia/eclampsia followed by obstetric hemorrhage (placenta previa, postpartum hemorrhage, rupture uterus), caesarean section complications and lastly medical condition associated with pregnancy.

Preeclampsia/eclampsia is one of the 3 leading causes of maternal morbidity and mortality worldwide, maternal complications of severe preeclampsia/eclampsia can be serious, leading to maternal, fetal, and neonatal morbidity and mortality. These include HELLP syndrome, disseminated intravascular coagulopathy and acute renal failure. Severe preeclampsia was found to be associated with an 8.7-fold risk of composite maternal complication (18). In our study, 11 cases of preeclampsia, 4 of them complicated with HELLP syndrome and 7 of them had fits. Worldwide, the incidence of preeclampsia ranges between $2 \%$ and $10 \%$ of pregnancies.

The incidence of preeclampsia, the precursor to eclampsia, varies greatly worldwide. WHO estimates the incidence of preeclampsia to be seven times higher in developing countries ${ }^{(19)}$. Eclampsia and PIH account for $13 \%$ of maternal death globally. Other studies reveal a large variation in eclampsia deaths between $50.56 \%$ and $16.3 \%{ }^{(20,21)}$. Other recent studies in Egypt differed and showed obstetric hemorrhage was the leading cause of death while the second cause of death in these studies was preeclampsia/eclampsia $(3,17)$.

Obstetric hemorrhage poses a significant threat to maternal health worldwide. It is one of the most important cause of maternal mortality, accounting for $25 \%$ to $30 \%$ of all maternal deaths worldwide. Complications associated with obstetric hemorrhage can range from mild to severe ${ }^{(22)}$. In our study obstetric hemorrhage was the cause of death in 7 cases, 4 of them died due to post-partum hemorrhage, 2 died because of rupture uterus and one with placenta previa.

According to three delays model, we found that most cases of maternal deaths due to $1^{\text {st }}$ delay 10 $(50 \%)$, that could explained as 8 cases of them were from rural areas where low socioeconomic status and lack of awareness of obstetric complications. All cases developed preeclampsia had no knowledge about obstetric complications and lack of importance of antenatal care. $3^{\text {rd }}$ delay was found in $4(20 \%)$ of cases, 2 of them died due to delayed intervention and 2 died due to surgical complications as bladder injury, bleeding and hematoma at the broad ligament with severe uterine atony. One case died due to $2^{\text {nd }}$ delay alone; the reason was late referral to ICU.

3 cases died due to combination of $1^{\text {st }}$ and $2^{\text {nd }}$ delays that was due to ignorance of obstetric complication, antenatal care importance combined with late arrival and lack of enough facilities in primary care unit. 2 cases died due to combination of $1^{\text {st }}$ and $3^{\text {rd }}$ delays due to ignorance of preeclampsia complications and occurrence of CS complication in one and long waiting time before ICU admission in the other case. That is agree with study from Nigeria concluded that $80 \%$ of mothers, who died in relation to pregnancy, belonged to the lower socio-economic class ${ }^{(23)}$ and with another study which concluded that $88 \%$ maternal mortality among the unbooked patients compared to $11 \%$ among the booked ${ }^{(24)}$. Similar results were found in studies by Kachhwaha and Jain ${ }^{(13)}$, Khandale et al. ${ }^{(25)}$ and Nair et al. ${ }^{(26)}$.

The first delay can be avoided by increasing the community awareness, by informing the pregnant woman about risks of her pregnancy and encouraging her to receive antenatal care also the danger of home delivery and the danger of delay to seek medical care and this will help in decreasing most of the indirect causes of maternal death ${ }^{(27)}$.

The second delay can be prevented by improving health system especially primary care centers, ambulance services and infrastructure, which is some sort difficult and need long-term national plan ${ }^{(28)}$. Also by improving the communications between university and the ministry of health to ensure better health care and to improve the outcome of the high risk cases. These communications between them may be in the form of referral communications, exchange of experiences, social health education and link with other specialties for cases that require multi-specialist management.

Third delay can be avoided by training physicians, nurses and midwives so that they can provide high quality, skilled maternal health care in the community, and by optimization the hospital needs with equipment to provide timely and adequate care in a friendly manner with respect to women as 
prerequisites to save the lives of women and newborns (29).

\section{CONCLUSION}

This study showed that the first delay is the most important delay in Sohag, especially in rural areas, and the most important cause of death was preeclampsia and ignorance about its complications, which was due to lack of antenatal care.

\section{RECOMMENDATIONS}

- We recommend application of three delay model on large scale in Sohag Governorate to clarify more weakness points as well as focusing on antenatal care program.

- Also, we recommend increasing facilities to educate mothers in rural areas as medical awareness campaigns, and surveys to pregnant women for early discover of preeclampsia or other diseases.

- Measuring maternal mortality and identifying its causes should be calculated regularly for the planning, monitoring and evaluation of maternal health care.

- Improve communication and link with other specialties for cases that require multi-specialist management.

- Revising the indication for caesarean section to avoid unnecessary sections because our study revealed that $80 \%$ of the maternal death was associated with cesarean section.

\section{REFERENCES}

1. WHO (2012): A global Trend in maternal mortality: 1990 to 2010 WHO, UNICEF, UNFPA and the World Bank estimates. https://www.who.int/reproductivehealth/publications/monitoring /9789241503631/en/

2. WHO, UNFPA, UNICEF and AMDD (2010): Monitoring Emergency Obstetric Care: A handbook, Geneva: WHO. http://whqlibdoc.who.int/ publications/2009/9789241547734 eng.pdf

3. Ghanem A, Saad K, Mostafa M et al. (2009): Forensic medical aspects of maternal mortality in Tanta University Hospita, Mansoura. Journal of Forensic Medicine Clinical Toxicology, 17: 1-14.

4. Wagstaff A, Claeson M (2004): The millennium development goals for health raising the challengs, World Bank. Available at: https://openknowledge.worldbank.org.

5. WHO, UNICEF, UNFPA and World Bank (2005): Maternal Mortality in 2005, Estimates Developed by WHO , UNICEF, UNFPA and World Bank, Geneva: WHO. Available at: http://www.who.int/whosis/mme_2005.pdf

6. Khalil K, Roudi-Fahimiam F (2004): Making motherhood safer in Egypt, PRB MENA Policy Brief available at: http://www.prb.org/pdf04/MakMotherSaferEgypt_Eng.pdf

7. Hamza $S$ (2005): The maternal mortality Egyptian national maternal mortality study Ain shams university. ASJOG., 83: 46271.

8. Villar J, Carroli G, Gulmezoglu A (2001): The gap between evidence and practice in maternal healthcare. Int $\mathbf{J}$ Gynecol Obstet., 75:547-554.

9. Dumont A, Gaye A, Mahe P et al. (2005): Emergency obstetric care in developing countries: impact of guidelines implementation in a community hospital in Senegal, BJOG., 112: 1264-9.

10. Zahran K, Fadel K, Ahmed S et al. (2016): Maternal mortality in an academic institution in Upper Egypt. Journal of Obstetrics and Gynaecology, 37(3):1-5.

11. USAID (2014): Measure evaluation population and reproducative health $(\mathrm{PRH})$, family planning and reproductive health indicators case fatality rate. available at: http://www.cpc.unc.edu/measure/prh/rh_indicator.

12. Bandeira A, Rezende $C$, Reis $Z$ et al. (2014): Epidemiologic profile, survival, and maternal prognosis factors among women at an obstetric intensive care unit. International Journal of Gynecology and Obstetrics, 124 (1):63-6.

13. Kachhwaha K, Jain M (2019): A Study of causes and factors responsible for maternal mortality in a tertiary care institute of Central Gujarat. Journal of Gynecology and Obstetrics, 7(4): 100103.

14. Karlsen S, Say L, Souza J, Hogue C, Calles D,Gulmezoglu A et $\boldsymbol{a l}$. The relationship betweenmaternal education and mortality among womengiving birth in health care institutions: analysis of thecross sectional WHO global survey on maternal and perinatal health. BMC Public Health, 11:606-609.

15. Souza J, Tunçalp Ö, Vogel J et al. (2014): Obstetric transition: the pathway towards ending preventable maternal deaths. BJOG., 121(1):1-4.

16. Hall M, Bewley S (1999): Maternal mortality and mode of delivery. Lancet, 354:776.

17. Saleh W, Ragab W, Aboulgheit S (2013): Audit of maternal mortality ratio and causes of maternal deaths in the largest maternity hospital in Cairo, Egypt (Kasr El-Aini) in 2008 and 2009. Lessons Learned African Journal of Reproductive Health, 17:105-109.

18. Ngwenya S (2017): Severe preeclampsia and eclampsia: incidence, complications, and perinatal outcomes at a lowresource setting, Mpilo Central Hospital, Bulawayo, Zimbabwe. International Journal of Women's Health, 9: 353-57.

19. Osungbade K, Ige $O$ (2011): Public health perspectives of preeclampsia in developing countries: implication for health system strengthening. Journal of Pregnancy, 2011:481095. https://www.hindawi.com/journals/jp/2011/481095/.

20. Amitava P, Prasanta R, Samir $\mathbf{H}$ et al. (2005): Review of changing trends in maternal mortality in a rural medical college in West Bengal. J Obstet Gynecol Ind., 55 (6): 521-4.

21. Salhan S, Sharma M, Suri J (2000): Maternal mortality in a tertiary hospital. JOSH, 7: 78-79.

22. Devine $P$ (2009): Obstetric hemorrhage. In Seminars in perinatology. WB Saunders, 33: 76-81.

23. Obi S, Ozumba B, Okaro J (2001): Emergency obstetric referrals at a university teaching hospital, Nigeria. East Afr Med J., 78: 262-264.

24. Uzoigwe $\mathbf{S}$, John $\mathbf{C}$ (2004): Maternal mortality in the University of Port Harcourt Teaching Hospital, Port Harcourt in the last year before the new millennium. Niger J Med., 13: 32-35.

25. Khandale S, Kedar K (2017): Analysis of maternal mortality: a retrospective study at tertiary care centre. Int J Reprod Contracept Obstet Gynecol., 6: 1610-3.

26. Nair A, Doibale M, Gujrathi V et al. (2016): Study of maternal mortality in a tertiary care hospital in a district of Maharashtra. Int J Med Sci Public Health, 5: 1851-1854.

27. McCarthy J, Maine D (1992): A framework for analyzing the determinants of maternal mortality. Stud Fam Plann., 23(1):2333

28. Gabrysch S, Campbell O (2009): Still too far to walk literature review of the determinants of deliveryservice use. BMC Pregnancy and Childbirth, 9:34-39.

29. Mo'men M, El Gelany S, Eladwy A et al. (2020): A ten year analysis of maternal deaths in a tertiary hospital using the three delays model. BMC Pregnancy and Childbirth, 20(1): 1-8. 